\title{
ANÁLISE DA PRECIPITAÇÃo PLUVIOMÉTRICA E A PRESENÇA DE NEVOEIROS NO ENTORNO PRÓXIMO DO RESERVATÓRIO DA USINA HIDRELÉTRICA DE DONA FRANCISCA EM AGUDO/RS
}

\author{
HOPPE, Ismael Luiz - ismael.hoppe@hotmail.com \\ Universidade Federal de Santa Maria / UFSM \\ WOLMANN, Cássio Arthur - cassio_geo@yahoo.com.br \\ Universidade Federal de Santa Maria / UFSM
}

\begin{abstract}
RESUMO: O presente artigo teve como objetivo, analisar a precipitação pluviométrica e a presença de nevoeiros durante o ano de 2014 em dois pontos distintos, em escala mensal, no entorno próximo do reservatório da Usina Hidrelétrica de Dona Francisca, localizada no município de Agudo/RS. Para a realização da pesquisa foram selecionados dois pontos de amostragem. Assim, foram utilizados pluviômetros artesanais para a coleta da precipitação pluviométrica. Observa-se que há uma diferença pluviométrica nos dois pontos da localidade estudada, associadas não à presença dos reservatórios, mas sim à posição dos pontos em relação ao relevo circundante. Nesse contexto, ainda se fazem necessários estudos mais aprofundados na área, de modo a se compreender a complexidade da dinâmica do clima local e assim identificar uma possível alteração ocorrida da formação do reservatório.
\end{abstract}

PALAVRAS-CHAVES: Precipitação, Nevoeiro, Pluviômetro, Usina Hidrelétrica, Reservatório.

ANALYSIS OF RAINFALL AND THE PRESENCE OF FOG IN THE SURROUNDINGS NEAR THE RESERVOIR OF THE DONA FRANCISCA HYDROELECTRIC POWER PLANT IN AGUDO/RS

\begin{abstract}
The present article concerns in to analyze rainfall and the presence of fog during 2014 at two distinct points on a monthly scale near the reservoir of the Dona Francisca Hydroelectric Power Plant, located in the city of Agudo/RS. Two sampling points were selected for the research. Thus, rain gauges were used to collect rainfall. It is observed that there is a pluviometric difference in the two points of the studied locality, associated not to the presence of the reservoirs, but to the position of the points in relation to the surrounding relief. In this context, further studies are still needed in the area, in order to understand the complexity of local climate dynamics and thus identify a possible change in reservoir formation.
\end{abstract}

KEYWORDS: Precipitation, Fog, Rain Gauge, Hydroelectric Power Plant, Artificial Lake

\section{INTRODUÇÃO}

Durante o século $X X$, inúmeras represas foram construídas visando satisfazer a crescente demanda por água e energia. Considerada como símbolo de modernização e da habilidade humana em controlar e utilizar recursos da natureza, a construção de grandes represas cresceu consideravelmente entre as décadas de 1930 e 1970 (CMR, 2000). Os cinco países com o maior número de represas incluem Estados Unidos, Canadá, Rússia, China e Brasil, que somam cerca de três quartos de todas as grandes represas do mundo e praticamente dois terços encontram-se nos países em desenvolvimento, como no Brasil (CMR, op. cit.).

O Brasil, em sua grande maioria, faz uso de energia elétrica produzida por usinas hidrelétricas (cerca de $95 \%$ ), isto se dá pelo fato do país possuir 
grandes mananciais de água, que permitem a utilização deste sistema. Contudo, em regiões rurais e mais afastadas a energia também pode ser gerada a partir de termoelétricas, e em menor escala, pode-se optar pela eólica (SOUZA; GALVANI, 2010).

A forma de funcionamento de uma Usina Hidrelétrica é a conversão do movimento das águas em energia, usando o potencial hidráulico de um rio. Essa forma de energia é a segunda maior fonte de eletricidade do mundo. Frequentemente constroem-se represas que barram o curso natural da água, fazendo com que ela se acumule em um reservatório denominado barragem. As represas de armazenamento alteram a distribuição e a periodicidade natural da vazão dos rios e são normalmente utilizados para a geração de energia elétrica, acumulação de água para abastecimento público e projetos de irrigação. A energia hidroelétrica representa mais de $90 \%$ da energia utilizada em países em desenvolvimento (CMR, 2000).

Cerca de metade das represas construídas tem a finalidade de acumular água para projetos de irrigação e acredita-se que estas contribuam com 12 a $16 \%$ da produção mundial de alimentos, gerando mudanças no uso e ocupação do solo nas diversas escalas de análise do espaço geográfico. Além disso, ao menos 75 países têm construído grandes represas para controlar inundações. (CRM, op. cit.).

É recomendável que, além dessas finalidades, o reservatório apresente outros usos como natação, pesca esportiva, esportes náuticos e fins paisagísticos. Apesar dos seus enormes benefícios, as barragens apresentam também algumas desvantagens, das quais se destacam a destruição de ecossistemas naturais com a inundação, perda de áreas agrícolas, deslocamento de cidades ou até mesmo o profundo impacto na paisagem e no clima (CEEE, 2008).

A construção de reservatórios artificiais, para implantação de usinas hidrelétricas, tem sido alvo de projetos para pesquisa de alguns autores nos últimos anos, que, quando possível basearam-se na análise de dados coletados, buscando conhecer a área antes e após a construção das barragens. Dentro nestas pesquisas, os autores sempre procuram evidenciar a maneira como estes lagos influenciaram no clima local. No entanto, apoiando-se nos resultados obtidos e descritos em tese, é possível compreender que a presença deste corpo hídrico não contribui para o aumento da temperatura e umidade relativa do ar, porém atua como um maior regulador térmico e higrométrico.

Rodrigues; Canônica (2006) investigaram as possíveis modificações no entorno da Usina Hidrelétrica de Itá, localizada na divisa entre Santa Catarina e Rio Grande do Sul, onde concluiu-se a não alteração no clima local, devido a presença do reservatório. No entanto, como já demonstrado em outras pesquisas meteorológicas em reservatórios, somente verificou-se o aumento da temperatura mínima e uma leve diminuição na temperatura máxima, com relação a outros pontos sem a influência do lago. Para Biavati; Fagundes; Souza; et. al. (2015), o clima ao entorno da Usina Hidrelétrica de Itá, não sofreu interferência por parte da represa com relação ao índice de precipitação, mantendo-se equilibrado ao longo dos meses de estudo.

Com isso, o presente artigo teve como objetivo analisar a precipitação pluviométrica e a presença de nevoeiros durante o ano de 2014 em dois pontos 
distintos, em escala mensal, no entorno do reservatório da Usina Hidrelétrica de Dona Francisca, localizada no município de Agudo / RS.

\subsection{CARACTERIZAÇÃO DA ÁREA}

A área de estudo está localizada no extremo norte do município de Agudo, no distrito de Nova Boêmia, na região central do Rio Grande do Sul. Encontra-se inserida na Microrregião de Restinga Seca e na Mesorregião do Centro Ocidental Rio-Grandense, a qual pertence a Quarta Colônia de Imigração Italiana (IBGE,2015).

Encontra-se a uma distância de $250 \mathrm{~km}$ de Porto Alegre, capital do Estado do Rio Grande do Sul, e sua área total é de 536,114 km². A população total segundo IBGE é de 17.110 habitantes, sendo 6.889 na área urbana e 9.833 na área rural e densidade demográfica é de 31,2 habitantes $/ \mathrm{km}^{2}$, e o Índice de Desenvolvimento Humano (IDH) é de 0,694 (IBGE, 2015).

Agudo faz divisa ao norte com os municípios de Ibarama e Lagoa Bonita; ao nordeste com Cerro Branco; a leste com Paraíso do Sul, à noroeste, faz divisa o município com Nova Palma, no oeste com o município Dona Francisca e, ao sudoeste com Restinga Seca. A área de estudo faz divisa somente entre os municípios de Agudo e Nova Palma e enquadra-se entre as coordenadas de $29^{\circ}$ $37^{\prime} 53^{\prime \prime}$ e $29^{\circ} 33^{\prime} 12^{\prime \prime}$ de latitude sul e $53^{\circ} 15^{\prime} 33^{\prime \prime}$ e $53^{\circ} 12^{\prime} 05^{\prime \prime}$ de longitude Oeste, conforme é mostrado na Figura 01. 


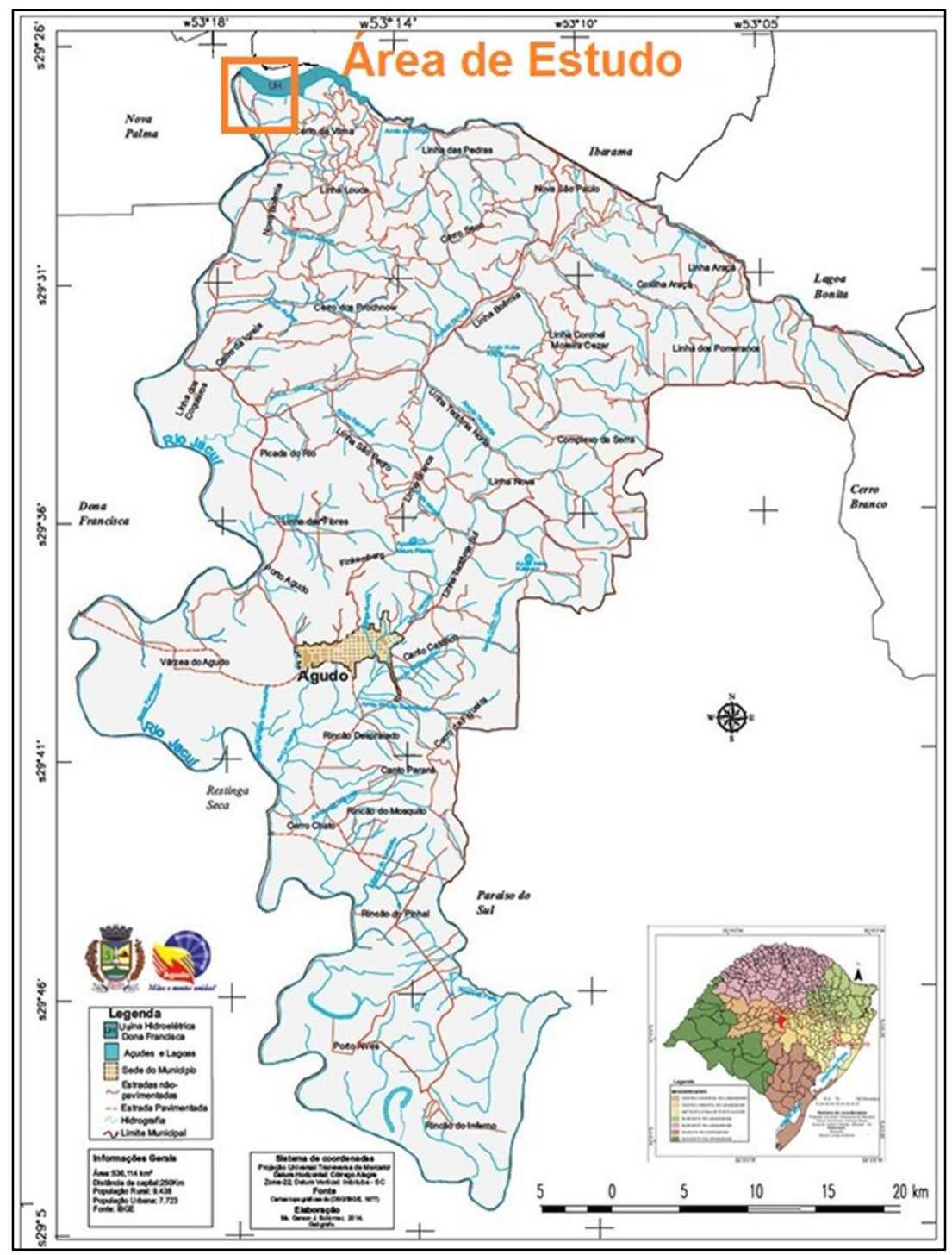

Figura 1 - Mapa político administrativo do município de Agudo - RS e localização da área de estudo. Fonte: Prefeitura Municipal de Agudo (Disponível em http://www.agudo.rs.gov.br).

O município de Agudo está na transição entre a Depressão Central e o Planalto da Bacia do Paraná. As rochas mais comuns encontradas no Planalto da Bacia do Paraná são da Formação Serra Geral, constituídas em sua maioria por basaltos; e abaixo, as rochas areníticas da Formação Botucatu, que formam o Aquífero Guarani, e são principalmente encontradas nas áreas de rebordo e das escarpas do planalto em contato com a Depressão Periférica.

Na Depressão periférica são encontradas grupos de rochas sedimentares antigas do Rio Grande do Sul provenientes da erosão do Planalto e do Escudo Sul Rio-Grandense desde o Pré-Cambriano (BREUNIG; PAZ; ROBAINA, PIRES, BRUM, 2003). 
O clima na área de estudos é definido como Cfa, subtropical úmido com verão quente, segundo a classificação de Köppen. As médias anuais são de 18 e $20^{\circ} \mathrm{C}$ e a precipitação pluviométrica abundante é de cerca de $2000 \mathrm{~mm} / \mathrm{ano}$, e são bem distribuídas ao longo do ano (KÖPPEN, 1931).

Segundo o Instituto Brasileiro de Geografia e Estatística (IBGE, 2015), o clima da região é classificado como subtropical superúmido sem seca, com temperaturas médias entre $10^{\circ} \mathrm{C}$ a $15^{\circ} \mathrm{C}$. As temperaturas na área de estudo, bem como no Estado do Rio Grande do Sul variam conforme as estações do ano. $\mathrm{Em}$ períodos de inverno, a temperatura média fica entorno de $10^{\circ} \mathrm{C}$ a $15^{\circ} \mathrm{C}$, as médias mínimas ficam entre $6^{\circ}$ e $10^{\circ} \mathrm{C}$ e nos verões a temperatura média é superior a $22^{\circ} \mathrm{C}$, enquanto que as médias das máximas variam entre os $28^{\circ} \mathrm{C}$ e $30^{\circ} \mathrm{C}$. Essa amplitude térmica se dá pela entrada de energia solar entre os solstícios e os equinócios e pela atuação das massas de ar sobre a região (SARTORI, 2003).

A umidade relativa do ar varia entre $70 \%$ e $85 \%$, sendo que nos verões é menor e nos invernos maior. Os ventos predominantes são de Leste e de Sudeste com velocidades médias de 1,5 a 2,0 m/s. Já na Depressão Central, o vento Leste predomina no inverno e na primavera, e no outono e no verão é o vento de Sudeste. Os ventos mais quentes e fortes são do quadrante Norte Noroeste, e os ventos mais frios são os de Sul e Sudoeste que são de leves a regulares em média. Os nevoeiros ocorrem principalmente de maio a agosto (maior umidade) e são mais frequentes na Depressão (SARTORI, 2003.).

Para o Rio Grande do Sul, especialmente para a área de estudo, os totais pluviométricos habituais são aqueles que ficam entre $1400 \mathrm{~mm}$ e $1800 \mathrm{~mm}$. Abaixo disto são considerados anos menos chuvosos e acima destes valores são considerados anos mais chuvosos. E o habitual pluviométrico entre as quatros estações do ano são de $350 \mathrm{~mm}$ a $450 \mathrm{~mm}$ por estação do ano (WOLLMANN; SARTORI, 2009), (SARTORI, 1993a, 1993c).

Os sistemas extratropicais que controlam a circulação secundária regional durante as estações do ano são representados pela Massa Polar Atlântica, Massa Polar Velha, Frente Polar Atlântica, enquanto que os sistemas intertropicais são de menor intensidade, e são representados pela Massa Tropical Atlântica e Massa Tropical Continental, Frente Quente de Nordeste e Instabilidades Tropicais. (SARTORI, op. cit.).

Segundo SEMA (2015), Agudo está inserido na Bacia Hidrográfica do Baixo Jacuí, que possui área de $17.345,15 \mathrm{Km}^{2}$. Entre os principais usos dos recursos hídricos dessa bacia têm-se a irrigação, o uso industrial, o abastecimento humano e não menos importante a geração de energia.

A vegetação na encosta do vale do rio Jacuí é integrante do domínio Mata Atlântica, que é um dos mais ameaçados do planeta. Após a intensa utilização da terra, que foi comum a prática de roçada e queimada pelo imigrantes que se estabeleceram no século XX, atualmente a vegetação está bastante degradada e em diferentes estágios de sucessão, composta por capoeira, mata secundária e mata ribeirinha (DURLO; MARCHIORI; LONGUI, 1982; LONGUI; MARCHIORI; LONGUI; DURLO, 1982; MARCUZZO; PAGEL; CHIAPPETTI, 1998), estando os maiores fragmentos restritos às áreas mais declivosas, ou mesmo protegidas por lei após construção das usinas, como ocorre na área de estudo. 


\section{FUNDAMENTAÇÃO TEÓRICA}

Para a fundamentação deste trabalho foi realizado um estudo baseado em referências especificas a respeito de cada assunto tratado neste trabalho, pois foi necessário para sua compreensão.

No primeiro momento, foi abordado o tema referente às escalas climáticas de modo a compreender em qual escala a área em análise se enquadra. E, como a localidade a ser avaliada encontra-se dentro do Estado do Rio Grande do Sul, foi preciso entender a dinâmica do clima da região, a qual foram selecionados autores que abordam em suas teses, o clima do Rio Grande do Sul e a maneira como se comportam os elementos climáticos, além de demonstrar por quais fatores são influenciados.

Segundo Sorre (1951), clima pode ser definido como o estudo da variabilidade do tempo em uma determinada região da superfície terrestre, baseando-se na sucessão dos diferentes tipos de tempo em um período mínimo de 30 anos. Enquanto o tempo meteorológico é somente um estado momentâneo da atmosfera em um dado local, referindo-se ao agrupamento de alguns fenômenos físicos, tais como: temperatura, umidade e ventos. Deste modo pode-se dizer que o clima possui um caráter dinâmico, e que se fazem necessárias observações periódicas dos seus elementos, com a finalidade de determinar se estes comportamentos são realmente permanentes.

Um importante meio para compreender o funcionamento do clima é a utilização de escalas, que servem de referência para o entendimento dos fenômenos climáticos em estudo, de uma determinada região. Podem ser divididas em cinco níveis: Zonal, Regional, Mesoclima ou Clima Local, Topoclima e Microclima (RIBEIRO, 1993). Além disso, para Serafini Jr et. al. (2010) as escalas possuem um importante papel, uma vez que elas priorizam um maior grau de detalhamento geográfico/climatológico, possibilitando um melhor conhecimento da dinâmica atmosférica predominante no local em análise.

A pesquisa realizada e apresentada neste trabalho utiliza como referencial a escala de clima local, uma vez que faz uso de equipamentos medidores de temperatura, umidade e precipitação para determinar a magnitude das trocas energéticas do local em estudo, respeitando suas particularidades fisiográficas e organização espacial e como estes fatores influenciam a variabilidade em áreas consideradas relativamente e pequenas e suas repercussões em seu entorno.

Para o estudo da área em questão, podem ser utilizadas duas formas de referência à caracterização do clima local: uma estatística, e outra genética. 0 método estatístico aborda os elementos climáticos e sua distribuição na superfície terrestre, usando técnicas estatísticas. A análise genética, por sua vez, estuda a dinâmica atmosférica recíproca à área de estudo, e avaliando noções de sistemas atmosféricas e sua dinamicidade (WOLLMANN; GALVANI, 2012). Os elementos climáticos que foram alvos deste estudo aplicam-se à análise estatística de clima, e são principalmente: a temperatura, umidade relativa do ar, precipitação e nevoeiros.

Dentro dos estudos sobre caracterização climática, um importante elemento a ser considerado é a precipitação pluvial. A precipitação pluviométrica para AYOADE (2002) pode ser definida como qualquer forma de deposição de água na forma liquida ou sólida provenientes da atmosfera (neve, granizo, 
orvalho, geada e nevoeiro). Sendo assim, a chuva é considerada como uma das três formas de precipitação, e ocorre no momento em que o vapor de água se condensa, formando nuvens sob ação da altitude, após saturação do ar, atingindo teoricamente $100 \%$ na atmosfera. Dessa maneira, desloca-se em direção a superfície em estado líquido ou sólido (PAULA, 2009).

Sua análise é relevante, pois a precipitação reflete não apenas as condições climáticas da área, mas também as sociais e econômicas, tornando-se um importante critério de análise e entendimento do espaço geográfico, devido ao fato de que pode demonstrar as condições de circulação atmosférica regional, tanto sazonal quanto anual (WOLLMANN; GALVANI, 2012), além de influenciar o planejamento das atividades agrícolas e econômicas da região em estudo. Também é considerada por Correa (2013), como o principal elemento de análise e organização do planejamento territorial e ambiental.

Sua medida pode ser dada através da medição do Índice Pluviométrico, o qual refere-se à quantidade de precipitação por metro quadrado de um determinado local e em um denominado período. O aparelho mais utilizado para esta medição é o pluviômetro, que consiste em um funil de captação e básculas utilizadas para recolher e medir a quantidade de precipitação liquida ou sólida. $E$ este valor varia em cada região do Brasil (INPE, 2015).

No Rio Grande do Sul, segundo Machado (1950), e afirmado em Sartori (2003) não existe uma estação que possa ser definida como chuvosa, uma vez que as precipitações se distribuem quase que com os mesmos valores ao longo do ano. Monteiro (1963), também aponta a ocorrência de chuvas no Estado, afirmando que estas se mantêm abundantes durante o ano todo, e que possui relação com o caráter úmido da região, destacando locais onde não é possível se identificar um período que possa ser considerado seco.

De acordo com Sartori (1993), os anos-padrões ou habituais, podem ser representados por aqueles anos em que os totais pluviométricos, para o Rio Grande do Sul, marcaram entre $1400 \mathrm{~mm}$ e $1800 \mathrm{~mm}$. Considerando que os valores abaixo deste total $(1400 \mathrm{~mm})$, assinalam os anos-padrões menos chuvosos e acima de $1800 \mathrm{~mm}$, os anos-padrões mais chuvosos.

Machado (1950) e Sartori (op. cit.), através da análise estatística de ambos autores, concluíram que os meses do ano oscilam com baixa diferença um do outro em relação a precipitação. Registrando no Estado que $27 \%$ das chuvas ocorrem no período da primavera, $28 \%$ a $31 \%$ nos meses do outono, $28 \%$ representado pelos de inverno e aproximadamente $17 \%$ no verão.

\section{PROCEDIMENTOS METODOLÓGICOS}

Para o desenvolvimento deste trabalho foram realizadas pesquisas na literatura sobre o assunto, seguido da coleta de dados na área. A escolha do tema surgiu devido ao fato de que há pouca ocorrência de trabalhos científicos baseados neste conteúdo no Brasil, e especialmente no Rio Grande do Sul, como verificado na revisão bibliográfica.

Nesse contexto, a escolha do Distrito de Nova Boêmia em Agudo, Rio Grande do Sul tem como objetivo de estudo por três razões: encontra-se localizado próximo ao reservatório da Usina hidrelétrica de Dona Francisca; pelo conhecimento da área em estudo, e pelo fácil acesso ao local por parte do autor. 
Foram selecionados dois pontos de amostragem para esta pesquisa. 0 ponto 01 está localizado na latitude de $29^{\circ} 29^{\prime} 21^{\prime \prime} \mathrm{S}$ e na Longitude de $53^{\circ} 1^{\prime} 7^{\prime}$ $17^{\prime \prime} \mathrm{O}$, com altitude de 75 metros acima do nível do mar. Encontra-se a uma distância de $1,41 \mathrm{~km}$ da margem do Lago e a 2,42 km do ponto 02 (mais ao sul). O ponto 02 está localizado na longitude de $29^{\circ} 28^{\prime} 36^{\prime \prime} \mathrm{S}$ e na longitude de $53^{\circ} 16^{\prime}$ 57" O, a uma altitude de 67 metros acima do nível do mar, e uma distância de $3,83 \mathrm{~km}$ do lago, conforme a figura 02 .

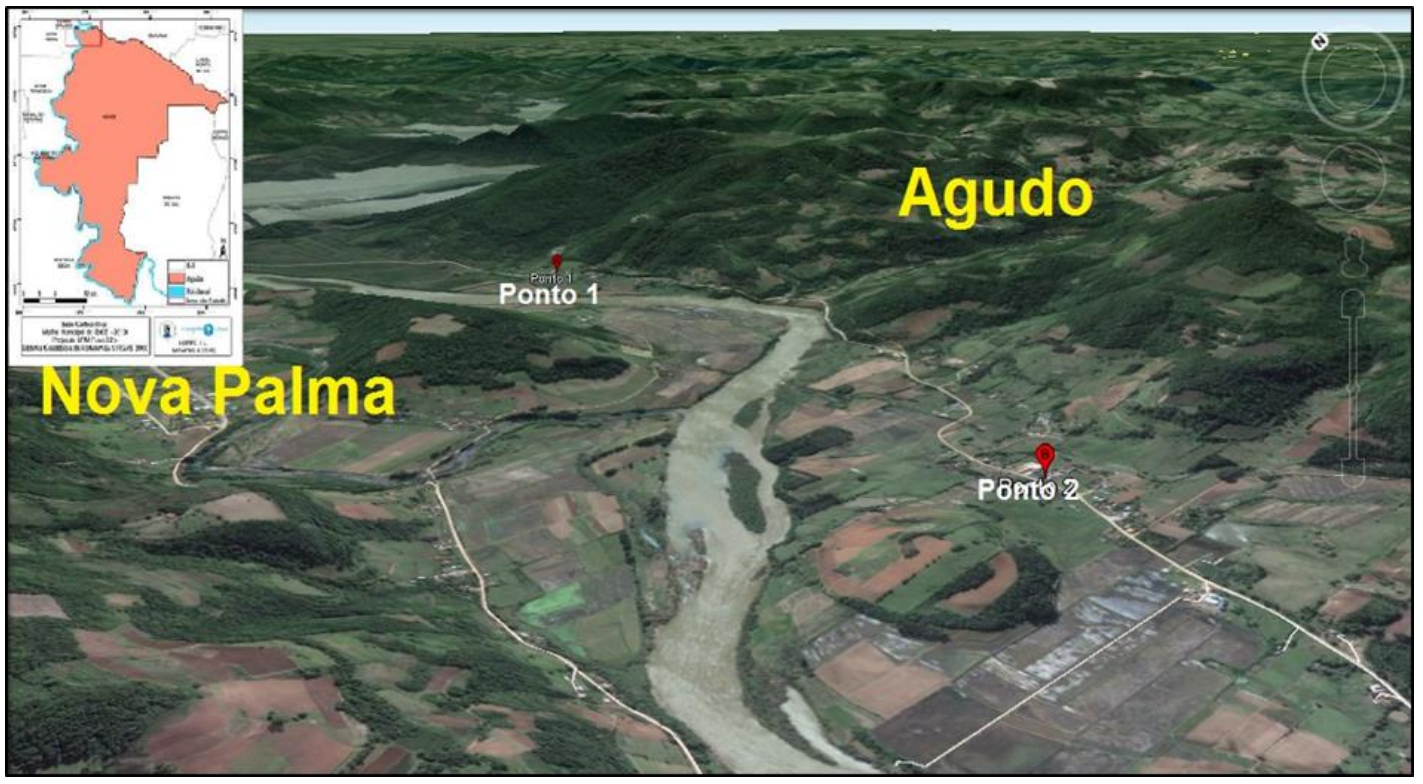

Figura 2 - Localização dos pontos de coleta. Fonte: Google Earth (2017).Org.: Os autores (2017).

Em um segundo momento foram confeccionados os pluviômetros proposto por Armani; Galvani (2006) e Milanesi; Galvani (2012), e testado por Hoppe, et. al. (2015). Estes pluviômetros já vêm sendo utilizado em outras pesquisas do Laboratório de Climatologia do curso de Geografia da Universidade Federal de Santa Maria, como em Wollmann, et. al. (2015). O pluviômetro foi feito de cano PVC (tamanho $100 \mathrm{~mm}$ ), com um funil de $16 \mathrm{~cm}$ de diâmetro instalado sobre a abertura superior, conforme metodologia de Milanesi; Galvani (op. cit), (Figura 03). 


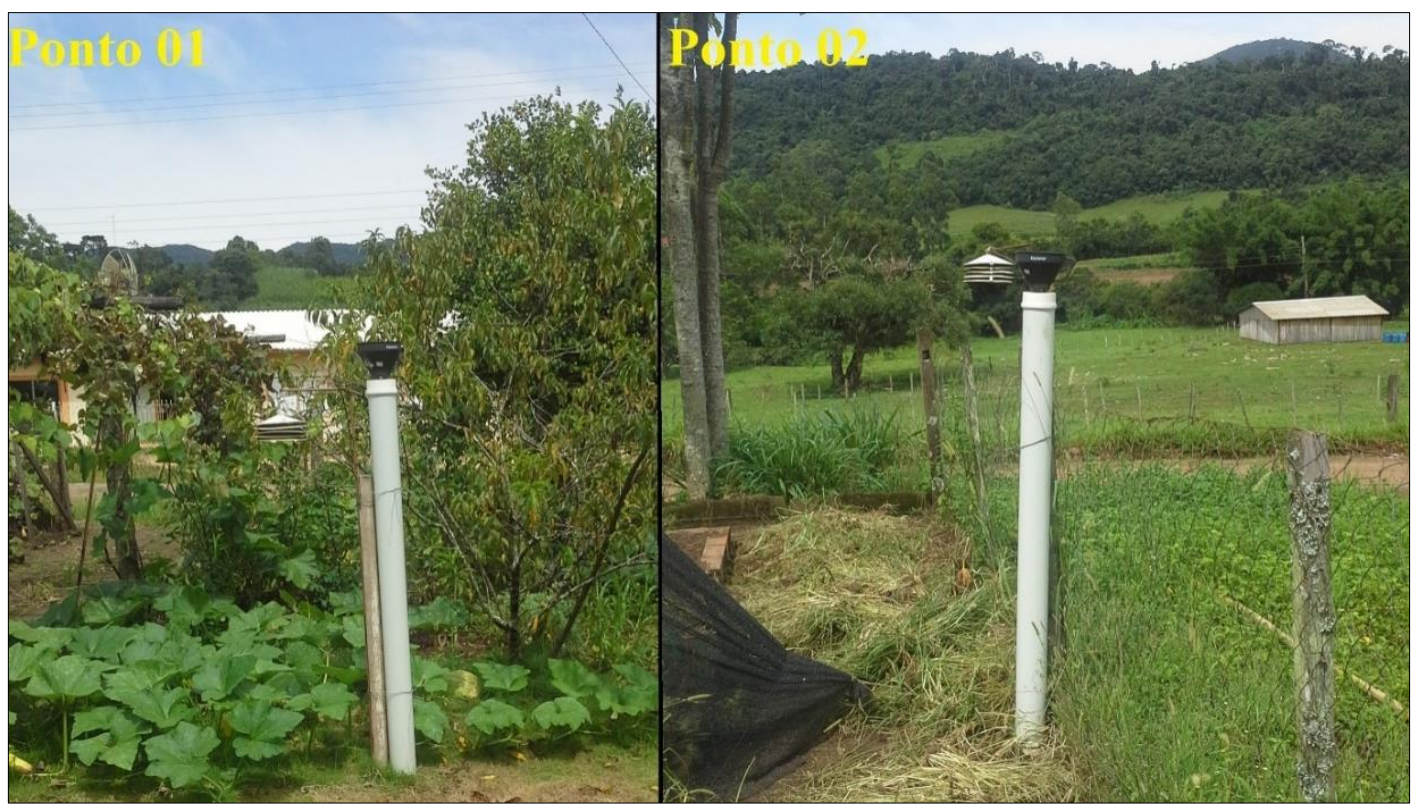

Figura 3 - Pluviômetros utilizados na área de estudo. Fotografia: Os autores, (2017).

Os pluviômetros foram instalados no dia 16 de dezembro de 2013 e recolhidos no dia 14 de janeiro de 2015. Para esse trabalho foram usados os dados de $1^{\circ}$ de janeiro de 2014 à 31 de dezembro de 2014, totalizando os 365 dias de coleta do ano de 2014. A coleta da água da chuva dos pluviômetros foi feita sempre no dia primeiro de cada mês, somando-se o total mensal precipitado.

As coletas da água dos pluviômetros foram realizadas no primeiro dia de cada mês (representando o total mensal precipitado) e a água coletada foi medida com o uso de um recipiente com capacidade para $2000 \mathrm{ml}$. A conversão matemática dos litros coletados no pluviômetro experimental foi realizada com base na fórmula $V=\pi R^{2} h$, onde $V$ é o volume coletado, $n$ é a constante $(3,14)$, $\mathrm{R}^{2}$ é o raio do funil e h é a altura da chuva (Milanesi; Galvani, 2012). Com os dados do diâmetro do funil, Hoppe, et. al. (2015), concluíram que cada litro de água armazenado corresponde a 48,4 $\mathrm{mm}$ de chuva precipitada.

Para observação e leitura da ocorrência de nevoeiros, foi feita observação diária in loco, com registro manuscrito dos dias de ocorrência, a qual foi realizada por morador local. Ao final, foi feita a contagem do número de dias de ocorrência de nevoeiros na área de estudo com a finalidade de se encontrar o total mensal e ocorrências desse fenômeno.

\section{ANALISE E DISCUSSÃo dOS RESULTADOS}

Em relação à precipitação pluviométrica a figura 04 apresenta o gráfico, em escala mensal de tabulação e análise, da chuva coletada e mensurada nos dois pontos de coleta entre os meses de janeiro de dezembro de 2014. 


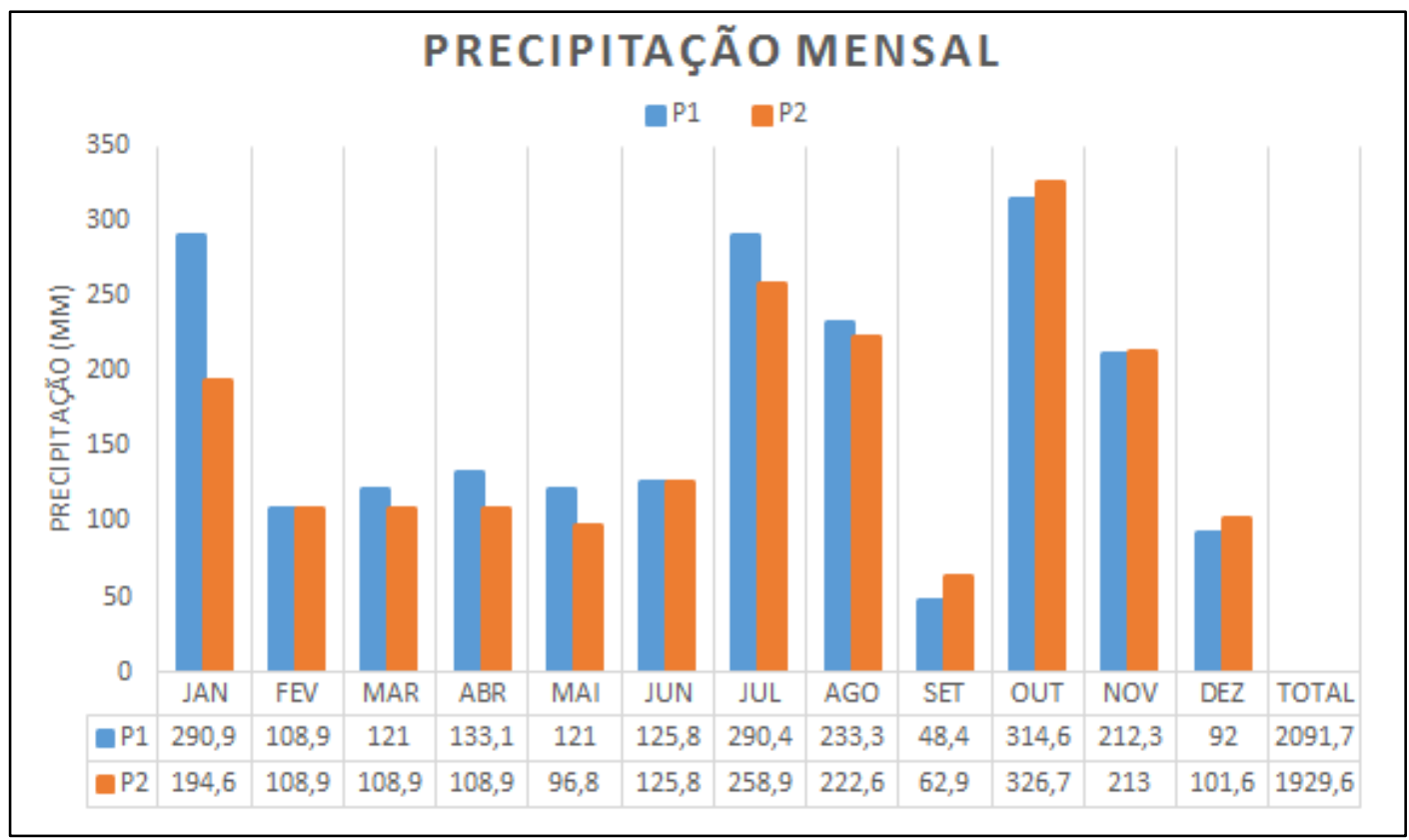

Figura 4 - Precipitação mensal registrada na área de estudo entre os meses de janeiro de dezembro de 2014. Org.: Os autores. (2017)

A precipitação pluviométrica coletada e registrada, conforme a figura 04 demonstrou que houve maior total de precipitação no ponto 01 em comparação com o ponto 02 ao longo dos 08 primeiros meses de análise (de janeiro a agosto). Entretanto, verifica-se que nos meses de setembro, outubro e dezembro, o total de precipitação do ponto 02 superou a do ponto 01 . O mês que maior apresentou variabilidade entre um ponto e outro foi janeiro, com variação de $96,3 \mathrm{~mm}$ do ponto 01 sobre o ponto 02 .

Tal fato decorreu, provavelmente, pela ocorrência de chuvas convectivas, mais comuns no período vernal e que ocorrem de forma localizada, comuns quando há intensa evaporação da água, provocada pelas altas temperaturas. Nos demais meses ocorreu uma maior precipitação no ponto 01 , o que pode estar relacionado ao efeito orográfico que se dá quando os sistemas atmosféricos atingem áreas com maior altimetria, como pode ser visto na figura 2. Neste caso, esses sistemas atmosféricos começam a ganhar altitude, favorecendo a condensação e consequente aumento na formação de chuvas.

Analisando-se o total pluviométrico anual, no ponto 01 registrou-se um total de $2091,7 \mathrm{~mm}$ de precipitação durante todo o ano de 2014 , e o ponto dois registrou $1929,6 \mathrm{~mm}$ durante o mesmo período. Nesse contexto, registrou-se uma diferença de $8,3 \%$ do ponto 01 para o ponto 02 , com total de $162,1 \mathrm{~mm}$ de precipitação. Nesse sentido, observa-se que a área de estudo, caso este tenha sido, de fato, um ano-padrão habitual, é mais chuvosa que os totais anuais de chuva apresentados por Sartori (1993, 2003), que apontavam para a região totais médios de até $1800 \mathrm{~mm}$ anuais, sendo os valores acima destes, já considerados anos-padrão mais chuvosos. 
Na a tabela 01 é possível observar o índice de precipitação pluviométrica referente às estações do ano seguido de suas médias e percentual de precipitação por estação.

Tabela 1 - Comparação sazonal entre o total de chuva precipitada nos pontos 01 e 02, e percentual de participação das chuvas nas estações do ano.

\begin{tabular}{crrrrr}
\hline & Verão & Outono & Inverno & Primavera & Total \\
\hline Ponto 01 & 491,8 & 371,5 & 649 & 575,3 & 2091,7 \\
\hline Ponto 02 & 405,2 & 314,6 & 607,3 & 602,6 & 1929,6 \\
\hline Média (01 e 02) & 448,5 & 343,0 & 628,4 & 589,0 & 2088,9 \\
\hline \% por Estação & 22 & 18 & 31 & 29 & 100 \\
\hline
\end{tabular}

Org: Os autores, (2017).

Nesse sentido, observa-se que as chuvas nos dois pontos da localidade estudada, com as devidas diferenças registradas em suas coletas, não apresentaram relação com a presença do reservatório, mas sim relacionadas à posição dos pontos em relação ao relevo circundante, que pode favorecer maior concentração de chuvas no ponto $01 \mathrm{em}$ comparação ao ponto 02, evidenciando-se leve efeito orográfico.

Para averiguar se houve influência do reservatório sobre os totais pluviométricos na região, isso só seria possível somente com um estudo de longo prazo, com utilização de dados anteriores e posteriores à construção da barragem. Infelizmente não há dados anteriores à construção da Usina Hidrelétrica de Dona Francisca na área de estudo. Ainda, conforme apontam os pesquisadores nas demais regiões do Brasil, com exceção do Nordeste, a presença de reservatórios artificiais não promove aumento das chuvas em seu entorno próximo em comparação com pontos mais distantes.

A figura 05 apresenta o gráfico relativo ao número total de dias de ocorrência de nevoeiros por mês no entorno próximo da represa da Usina Hidrelétrica de Dona Francisca.

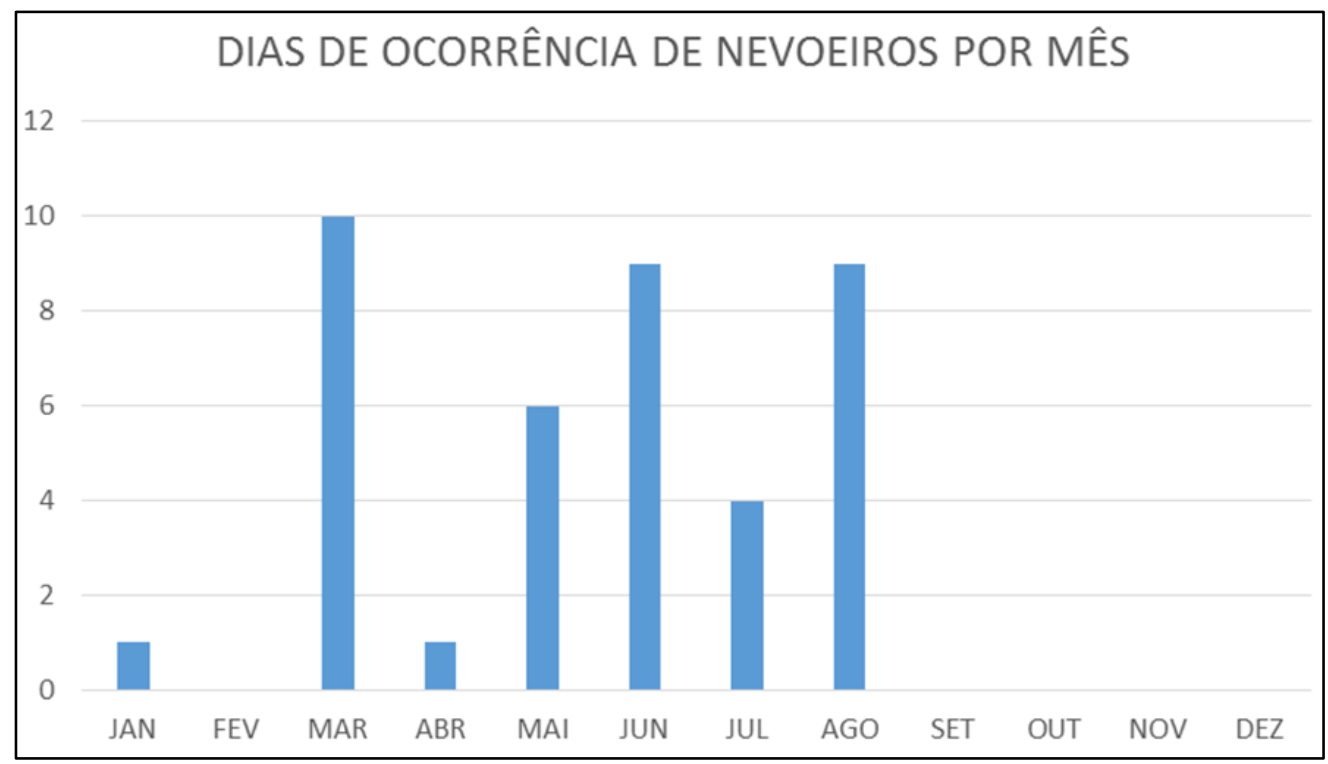

Figura 5 - Dias de ocorrência de nevoeiro por mês.Org.: Os autores. (2015) 
A figura 05 apresenta o total de dias de ocorrência de nevoeiros em cada mês. Na figura pode-se verificar que no mês de janeiro e abril tiveram apenas um dia em cada mês a presença de nevoeiro, e em março foi o maior pico, registrando-se 10 dias com presença de nevoeiro. No mês de maio foram registrados 6 dias, julho e agosto foram registrados 9 dias e em julho, 4 dias. Os meses de fevereiro, setembro, outubro, novembro e dezembro não houve ocorrência de nevoeiro.

O alto número de ocorrências de nevoeiros em março chama a atenção dado que Sartori (2003) coloca que na depressão periférica é comum a ocorrência deste fenômeno de maio a agosto, o que de fato também ocorreu. No entanto, ocorre que o mês de março é fim do verão início do outono, tanto astronômico quanto climático para o Rio Grande do Sul, e neste período a água do reservatório ainda se encontra mais quente devido ao aquecimento intenso do verão, deixando a água mais quente (inércia térmica) em uma época que já não se registra tanto calor. Com a chegada do outono, intensificam-se os sistemas polares, especialmente as massas de ar, que ao chegarem sobre a região mais fria, encontram uma superfície líquida ainda aquecida do verão, a qual pode favorecer a formação de nevoeiros, especialmente do tipo advectivo, que ocorrem quando a água mais quente, mais propícia à evaporação, condensa-se na atmosfera com a chegada de massas de ar mais frias.

Pode-se dizer que durante o ano de 2014 os nevoeiros dominaram durante $10,5 \%$ dos dias do ano, e concentraram-se nos períodos outonais e invernais, quando a atmosfera torna-se mais úmida, o que ficou evidenciado nas análises dos gráficos da figuras 04 a 05, as quais registraram os maiores valores de umidade e suas variantes na área de estudo justamente nesses meses, corroborando com Sartori (2003) que identificou a ocorrência de nevoeiros na Depressão Periférica do Rio Grande do Sul entre os meses de maio a agosto.

Não se pode concluir que houve aumento ou não de nevoeiros em função da construção do reservatório da Usina Hidrelétrica de Dona Francisca, haja visto a inexistência de dados anteriores à existência desse. Porém, é relatado por moradores da localidade que este fenômeno se tornou mais intenso e frequente após a criação do reservatório.

No entanto pesquisas mais detalhadas para este tema são necessárias no futuro, a fim de que se possa investigar a percepção climática dos moradores do entorno de lagos artificiais de grandes áreas, com a da Usina Hidrelétrica de Dona Francisca. Nesse sentido, a análise da ocorrência de nevoeiros na área de estudo durante o ano de 2014 tem apenas um caráter especulativo e propositivo. Espera-se continuar esta medição e consultar por meio de técnicas propicias, a população local sobre este fato.

\section{CONCLUSÕES}

O estudo realizado na área próxima à da Usina Hidrelétrica da represa da Dona Francisca, no distrito rural de Nova Boêmia, no município de Agudo/RS, serviu para verificação de possíveis influências deste corpo hídrico artificial na porção de chuva no local. Para determinar essa possível influência foram instalados dois pluviômetros com a finalidade de obter dados da precipitação, colocados em dois pontos próximos ao reservatório, conforme bibliografia consultada e metodologia testada em outras áreas do Brasil. 
Em relação aos totais pluviométricos, registrou-se maior precipitação no ponto 01 em comparação ao ponto 02 , e isso ocorre devido à maior proximidade com o rebordo do planalto, favorecendo o efeito orográfico. A maior concentração de nevoeiros observados foi registrada de março a agosto, pois nessa época o ar mais frio tende a facilitar os processos de condensação da água na atmosfera.

Nesse sentido, observa-se que as chuvas nos dois pontos da localidade estudada, com as devidas diferenças registradas em suas coletas, estiveram associadas não à presença dos reservatórios, mas à posição dos pontos em relação ao relevo circundante, que pode favorecer maior concentração de chuvas no ponto 01 em comparação ao ponto 02, evidenciando-se leve efeito orográfico.

Para averiguar se há influência do reservatório sobre os totais pluviométricos na região, só seria possível com um estudo de longo prazo, com utilização de dados anteriores e posteriores à construção da barragem. Infelizmente não há dados anteriores à construção da Usina Hidrelétrica de Dona Francisca na área de estudo. Ainda, conforme apontam os pesquisadores nas demais regiões do Brasil, com exceção do Nordeste, a presença de reservatórios artificiais não promove aumento das chuvas em seu entorno próximo em comparação com pontos mais distantes.

Nesse contexto, ainda se fazem necessários futuros estudos mais aprofundados na área, de modo a se compreender a complexidade da dinâmica do clima local destes locais e assim identificar uma possível alteração ocorrida da formação do reservatório da Usina Hidrelétrica de Dona Francisca em Agudo/RS.

\section{REFERÊNCIAS}

ARMANI, G.; GALVANI, E. Avaliação do desempenho de um abrigo meteorológico de baixo custo. Revista Brasileira de Agrometeorologia, Piracicaba-SP, v. 14, n.1, p. 116-122, 2006

AYOADE, J. O. Introdução a Climatologia para os Trópicos. 10. ed. Rio de Janeiro: Bertrand Brasil, 2002.

BREUNIG; F. M; PAZ; M. O; ROBAINA; L. E. S; MEDEIROS; E. R; PIRES; C. A; BRUM L. O Rio Grande do Sul através do tempo geológico: proposta didática. Simpósio Brasileiro de Geografia Física Aplicada. 10. Anais. Rio de Janeiro. 2003.

BIAVATI, A.; FAGUNDES, R. A.; SOUZA, D.; SANCHES, F. A influência do lago da UHE de Itá nas precipitações mensais em Marcelinho Ramos (RS). In: SIMPÓSIO BRASILEIRO DE GEOGRAFIA FÍSICA APLICADA. 16. Anais... Piauí, 2015.

CEEE. GERAÇÃo DE ENERGIA. Planos de uso e ocupação do solo do entorno dos reservatórios do Sistema Jacuí. Disponível em: <http://www.ceee.com.br/pportal/ceee/Component/Controller.aspx?CC=1753>. Acesso em 23 de outubro de 2008. 
COMISIÓN MUNDIAL DE REPRESAS (CMR). Represas y desarrollo: un nuevo marco para la toma de decisiones, Comissión Mundial de Represas. Reporte Final, novembro de 2000. p. 404.

COMPANHIA ESTADUAL DE ENERGIA ELÉTRICA (CEEE) - Relatório de Impacto Ambiental Usina Hidrelétrica de Dona Francisca. 2008. Disponível em: <https://www.fundacaoceee.com.br/documentos/demonstrativos/2008/Relatori o_CEEE_2008.pdf>. Acesso em 05 de novembro de 2015.

CORREA, M. G. G. Distribuição espacial e variabilidade da precipitação pluviométrica na bacia do rio Piquiri - PR. Dissertação (Mestrado em Geografia) Universidade de São Paulo, São Paulo, 2013.

DURLO, M. A.; MARCHIORI, J. N. C.; LONGUI, S. J. Composição e estrutura da mata secundária no vale do rio Jacuí, RS. Ciência \& Natura, v. 4, p. 129-139, 1982.

GALVANI, E.; LIMA, N. G. B. Climatologia Aplicada: Resgate aos estudos caso. 1. ed. Curitiba: CRV, 2012. v. 1. 192 p.

GUIDON, M. A. A. de O. Estudo das variações climáticas na área do lago de Tucuruí. 2 v. Dissertação (Mestrado em Geografia) -Universidade de São Paulo, São Paulo, 1991.

HOPPE, I. L.; IENSSE, A. C.; SIMIONI, J. P. D.; WOLLMANN, C. A. Comparação entre um abrigo meteorológico de baixo custo e a estação meteorológica oficial no INMET, em Santa Maria (RS). Ciência e Natura, v. 37, p. 132-137, 2015.

IBGE - INSTITUTO BRASILEIRO DE GEOGRAFIA E ESTATÍSTICA. IBGE Cidade. Dados censitários do município de Agudo/RS. Disponível em: http://www.cidades.ibge.gov.br/xtras/perfil.php?lang =\&codmun $=430637$ \&searc $\mathrm{h}=$ rio-grande-do-sul|dilermando-de-aguiar|infograficos:-informacoes-completas. Acesso em 06 de jul. 2015.

INPE - Instituto Nacional de Pesquisa Espacial. Disponível em: http://www.inpe.br/acessoainformacao/node/402. Acesso em: 05 de setembro de 2015

KÖEPPEN, W. Climatología. Buenos Aires: Fondo de Cultura Económica. 20 ed. 1931.

LONGUI, S. J.; DURLO, M. A.; MARCHIORI, J. N. C. A vegetação da mata ribeirinha no curso médio do rio Jacuí, RS. Ciência e Natura, v. 4, p. 151-161, 1982.

MACHADO, F. P. Contribuição ao estudo do clima do Rio Grande do Sul. Rio de Janeiro: Serviço Geográfico do IBGE, 1950.

MARCHIORI, J. N. C.; LONGUI, S. J.; DURLO, M. A. A vegetação de capoeira na região do curso médio do rio Jacuí, RS. Ciência \& Natura, v. 4, p. 141-150, 1982.

MARCUZZO, S.; PAGEL, S. M.; CHIAPPETTI, M. I. S. A Reserva da Biosfera da Mata Atlântica no Rio Grande do Sul: situação atual, ações e perspectivas. São Paulo, Consórcio da Mata Atlântica e Conselho Nacional da Reserva da Biosfera da Mata Atlântica. Caderno 11, 1998. 60p. 
MILANESI, M. A.; GALVANI, E. Pluviômetro Experimental Para Localidades Remotas. In.: Climatologia Aplicada: Resgate aos Estudos de Caso. Galvani, E.; Lima, N. G. B. (Orgs.). Curitiba: Editora CRV, 2012. v. 1. 1 ed. p.192.

MONTEIRO, C. A. F. O clima da região Sul. In: CATALDO, D. M. (Org.) Geografia do Brasil, Grande Região Sul. Rio de Janeiro: IBGE, 1963. p. 117-169.

NOAA. Southern Oscillation Index (SOI). Disponível em: <http://www.ncdc.noaa.gov/teleconnections/enso/indicators/soi/>. Acesso em 10 Nov. 2015.

PAULA, G. M. de. O fenômeno El Niño Oscilação Sul e a Erosividade das Chuvas em Santa Maria, RS. 2009. 55f. Dissertação (Mestrado Em Engenharia Agrícola) - Universidade Federal de Santa Maria. 2014.

PREFEITURA MUNICIPAL DE AGUDO. Mapa Político-administrativo de Agudo/RS. Disponível em: <http://www.agudo.rs.gov.br/home>. Acesso em 25 de agosto de 2015.

RIBEIRO, A. G. As escalas do Clima. Boletim de Geografia Teorética. Vol.23 (4546). 1993.

RODRIGUES, M. L. G.; CANÔNICA, E. Análise preliminar do impacto reservatório de Itá no clima local. In: Congresso Brasileiro de Meteorologia. XIV. Anais... Florianópolis, 2006.

ROSSATO. M. S. Os climas do Rio Grande do Sul: variabilidade, tendências e tipologia.2011. 253 f. Tese (Doutorado em Geografia) - Universidade Federal do Rio Grande do Sul, Porto Alegre, 2011.

SARTORI, M. G. B. Distribuição das chuvas no Rio Grande do Sul e a variabilidade têmporo-espacial no período 1912-1984. In: SIMPÓSIO BRASILEIRO DE GEOGRAFIA FÍSICA E APLICADA. 5. São Paulo: USP, Anais... 1993a. p. 275-280.

SARTORI, M. G. B. A circulação atmosférica regional e os principais tipos de Sucessão do Tempo no Inverno do Rio Grande do Sul, RS. Ciência e Natura, UFSM, 15: 69-93, 1993b.

SARTORI, M. G. B. As Variações Pluviométricas e o Regime das Chuvas na Região Central do Rio Grande do Sul. Boletim de Geografia Teorética, 23 (4546): 70-84, 1993c.

SARTORI, M. G. B. A dinâmica do Clima do Rio Grande do Sul: indução empírica e conhecimento científico. 2003, Terra Livre, São Paulo, Ano 19 - Vol. I n.20, P 27-49, Jan/jul. 2003

SEMA. SECRETÁRIA DO AMBIENTE E DESENVOLVIMENTO SUSTENTÁVEL. Disponível em: <http://www.sema.rs.gov.br/>. Acesso em 22 de junho de 2015.

SERAFINI JUNIOR, S.; GALVANI, E.; LIMA, N. A. G. B.; ALVES, R. R. Adequação da escala climatológica na análise climática para planos de manejo: o Parque Estadual Intervales como estudo de caso. In: Emerson Galvani; Nádia Gilma Bezerra de Lima. (Org.). Climatologia aplicada: resgate aos estudos de caso. 1ed. Curitiba: Editora CRV, 2012, v. 01, p. 43-54. 
SORRE, M. Les Fondements de la Géograhie Humaine. Tome Premier: Les fondaments biologiques. Paris: Armand. Colin, 1951.

SOUZA, M. B; GALVANI, E. Formação de Reservatórios e Influências no Microclima: Estudo da cidade de Presidente Epitácio, Estado de São Paulo, Brasil. In: VI Seminário Latino-americano de Geografia Física e II Seminário Ibero-americano de Geografia Física. Anais. Universidade de Coimbra, Portugal, 2010.

VAREJÃO - SILVA, M. A. Umidade relativa do ar. In: Meteorologia e climatologia. Recife: Versão Digital 2, 2006. p.133-155.

WOLLMANN, C. A. SARTORI, M. G. Frequência mensal e sazonal da participação de sistemas atmosféricos no verão do Rio Grande do Sul: análise sobre três casos típicos (1986/1987, 1997/1998 e 2004/2005). 2009, Ciência e Natura, UFSM, 31 (1): p.141-161, 2009.

WOLLMANN, C. A. Zoneamento agroclimático para a produção de roseiras (Rosaceae spp.) no Rio Grande do Sul. (Tese de Doutorado) Universidade de São Paulo, 2011.

WOLLMANN, C. A.; GALVANI, E. Caracterização Climática Regional do Rio Grande do Sul: dos estudos estatísticos ao entendimento da gênese. Revista Brasileira de Climatologia. Vol. 11. Ano: 8. Pág. 87-103. 2012.

WOLLMANN, C. A.; SIMIONI, J. P. D.; IENSSE, A. C. Atlas climático da Estação Ecológica do Taim: Contribuição ao estudo do clima em unidades de conservação no Rio Grande do Sul. 1. ed. Santa Maria: O autor. 2015. 300p. 